\title{
Kinetics study on non-isothermal thermochemical liquefaction of corncobs in ethanol-water solution: Effect of ethanol concentration
}

\author{
Bregas Siswahjono Tatag Sembodo ${ }^{1,2,}$, Hary Sulistyo ${ }^{2}$, Wahyudi Budi Sediawan ${ }^{2}$, and Mohammad Fahrurrozi ${ }^{2}$ \\ ${ }^{1}$ Universitas Sebelas Maret, Chemical Engineering Department, J1. Ir. Sutami 36 A, Surakarta 57126, Indonesia \\ ${ }^{2}$ Universitas Gadjah Mada, Chemical Engineering Department, Jl. Grafika no.2, Yogyakarta 55281, Indonesia
}

\begin{abstract}
Corncobs are potentially processed into bio-oil through thermochemical liquefaction processes. It is difficult to construct kinetics models based on the compounds involved in the reaction. It would be made four kinetic models based on four reaction products, i.e., solids, bio-oil, gas and volatile products. The purposes of the study were to seek kinetics model of thermochemical liquefaction of corncobs in ethanolwater solution and to study the effect of ethanol concentration. The experiment of liquefaction processes of corncobs in ethanol-water solution using sodium carbonate catalyst was performed in the $150 \mathrm{ml}$ autoclave equipped with a magnetic stirrer in the temperature up to $280^{\circ} \mathrm{C}$. Four kinetic models were applied to predict the yield of four reaction product lumps. The calculation results were compared to the experimental data. Compared to the others, model 4 was the most realistic and closely matching to the experimental data. In model 4 the reaction mechanism was assumed that biomass (corncobs) first decomposed into bio-oil, followed by decomposition of bio-oil into volatile products reversibly and, finally, volatile products decomposed into gaseous products. The yield of bio-oil increased from $42.05 \%$ to $54.93 \%$ by increasing to ethanol concentration of $0 \%$ to $40 \%$.
\end{abstract}

\section{Introduction}

As economic and human population growth, the world's energy needs are also increasing. Unfortunately, most of the world's energy needs now are still met from fossil fuels, which are limited, non-renewable and environmentally unfriendly. Since long time ago many scientists have searched for alternative energy sources that have positive properties and contrary to the nature of fossil fuels, as well as finding a process technology to convert them into applicable fuels. One of the alternative energy sources that possesses these characters is biomass. Meanwhile, thermochemical technology have been developed to convert biomass into energy besides biochemical technology [1].

The main biomass thermochemical conversion technologies are gasification, hydrothermal liquefaction (thermochemical liquefaction), pyrolysis, direct combustion, and supercritical fluid extraction. The advantages of thermochemical liquefaction process over other thermochemical processes are that is able to process wet biomass and require relatively lower operating temperatures [2].

The use of methanol and ethanol solvent in the liquefaction of Ulva fasciata algae could produce bio-oil with yield of $44 \%$ and $40 \%$, instead of using water solvent reaching only $11 \%$. Alcohol compounds were also useful in converting organic acid compounds in biooil to esters. Alcohol compounds were also capable of lowering oxygen content in bio-oil and producing more valuable hydrocarbon compounds with hydrogen and carbon elements from biomass [3].

Liu and Zhang [4] and Wang et al. [5] examined the effect of solvent types on thermochemical liquefaction of pine wood. Their results showed that the yield of bio-oil is higher with solvents of ethanol than with water solvents or acetone.

Biomass decomposition by thermochemical liquefaction processes involves many complex compounds and reactions $[6,7]$. Therefore, the reaction rate equations are not arranged according to the compounds involved, but are arranged according to the pseudo-component or group of compounds separated by phase difference in the room temperature.

Some researchers conducted kinetics studies of thermochemical liquefaction against biomass or cellulose. Zhang et al. [8] developed seven models of thermochemical liquefaction kinetics of grassland perennials based on groups of compounds according to their phases, namely solid (biomass), liquids, gases and char. All models are still based on isothermal reactions. The reaction mechanism model closest to the experimental data was that biomass was decomposed as a parallel reaction to liquid, gas and char.

Shi et al. [7], Zhang et al. [9], and Zhang et al. [10] formulated the effect of temperature on the rate of solid decomposition of cellulose or biomass regardless of the

* Corresponding author: bregas@staff.uns.ac.id 
mechanism of the reaction. The rate of solid decomposition was measured with thermo gravimetric analysis. The developed model was able to calculate the decomposition rate, but this model had not yet taken into account the rate of liquefaction products formation.

The study of thermochemical liquefaction processes on corncobs in water medium was done by Gan and Yuan [11]. In the study, it was studied about the quantity and quality of liquefaction products, instead of studying the kinetics.

Valdez and Savage [12] studied the mechanism and kinetics of thermochemical liquefaction reactions of Nannochloropsis $s p$. isothermally. There are five lumps involved in the reaction, i.e., solids, heavy biocrude, light biocrude, aqueous phase products, and gas.

So far, no researcher studied the mechanism and kinetics of thermochemical liquefaction reaction nonisothermally on biomass, especially corncobs.

The objectives of the research were to study on the mechanism and kinetics of thermochemical liquefaction of corncobs in the ethanol-water solution nonisothermally and the effect of ethanol concentration towards the rate of bio-oil production.

\section{Methods}

The corncobs, as the main raw material in the research, were obtained from Wonogiri, Central Java. The corncobs were dried under sunshine for about 6 hours. The dried corncobs were grinded and sieved to particle size of 40 mesh to obtain corncobs powder. The powder was further dried in the oven at $100^{\circ} \mathrm{C}$ for 24 hours and stored in the sealed plastic bag. The corncobs powder was characterized for chemical composition analysis. The result was that corncob was mainly composed of $34.21 \%$ hemicellulose, $40.46 \%$ cellulose, and $11.36 \%$ lignin.

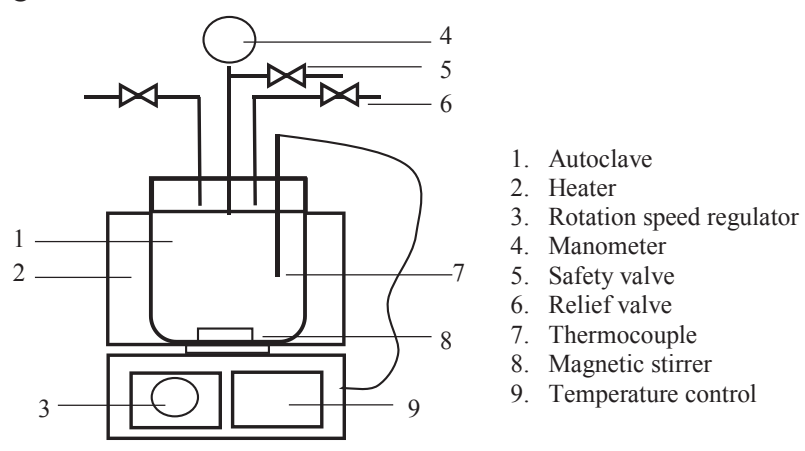

Fig. 1. The sketch of autoclave reactor.

The liquefaction process of corncobs in the ethanolwater solution experimentally carried out in the $150 \mathrm{~mL}$ autoclave reactor equipped with magnetic stirrer (Fig. 1). Four grams of corncob powder was put in the reactor, followed by the addition of 0.2 grams of $\mathrm{Na}_{2} \mathrm{CO}_{3}$ catalyst and $100 \mathrm{~mL}$ of ethanol-water solution. The ethanol-water solution was varied at $0 \%, 20 \%$ and $40 \%(\mathrm{v} / \mathrm{v})$. Nitrogen was blown into the autoclave for 4 minutes to dissipate air inside. The heating process was started at room temperature up to $280^{\circ} \mathrm{C}$. The liquefaction process was finished at a certain time for sampling, by stopping the heating process and being followed by cooling with air fan.

The products were taken after the reactor was cooled and reached the room temperature. The gas product was collected in a gas bag. The remaining product of the reaction was filtered through filter paper to obtain the solid product. The filtrate was evaporated by a rotary vacuum evaporator to obtain the bio-oil. The volatile product was calculated from the difference between the weight of the starting biomass and the weight of the final product.

The yield of products of liquefaction were defined as follows.

bio-oil yield $=\frac{\text { weight } \text { of bio-oil }}{\text { initial weight of biomass }}$

gas yield $=\frac{\text { weight of gas }}{\text { initial weight of biomass }}$

solid yield $=\frac{\text { weight of solid residue }}{\text { initial weight of biomass }}$

volatile yield $=1-($ bio-oil yield + gas yield + solid yield $)$

There were four product lumps, i.e. solid (S), bio-oil (B), volatile (V), and gas (G). It was developed four kinetic models for predicting the yield of four product lumps.

The actual reactions were quite complex. Therefore, the simplification of the reaction mechanism must be considered. All the reactions were assumed homogeneous and pseudo first order. The solid product were the biomass that has not been decomposed. It was assumed that there was no solid from reaction products. The ethanol-water solution was quite a lot in the system, so the solvent was not involved in the kinetic equations of the models. For all the kinetic equations, $x_{B}, x_{G}, x_{S}$, and $x_{V}$ are yield of bio-oil, gas, solid, and volatile, respectively.

\subsection{Model 1}

In this model, the reaction mechanism was assumed as depicted in Fig. 2.

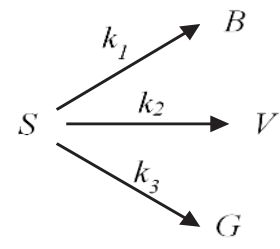

Fig. 2. Reaction scheme of model 1.

The kinetic equations of model 1 were as follows. $\frac{\mathrm{d} x_{B}}{\mathrm{~d} t}=k_{1} x_{S}$ 


$$
\begin{aligned}
\frac{\mathrm{d} x_{G}}{\mathrm{~d} t} & =k_{3} x_{S} \\
\frac{\mathrm{d} x_{S}}{\mathrm{~d} t} & =-\left(k_{1}+k_{2}+k_{3}\right) x_{S} \\
\frac{\mathrm{d} x_{V}}{\mathrm{~d} t} & =k_{2} x_{S}
\end{aligned}
$$

\subsection{Model 2}

In model 2, the reaction mechanism was assumed as shown in Fig. 3.

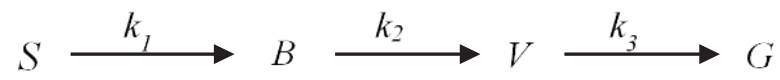

Fig. 3. Reaction scheme of model 2.

The kinetic equations of this model were as follows.

$$
\begin{aligned}
\quad \frac{\mathrm{d} x_{B}}{\mathrm{~d} t}=k_{1} x_{S}-k_{2} x_{B} \\
\frac{\mathrm{d} x_{G}}{\mathrm{~d} t}=k_{3} x_{V} \\
\frac{\mathrm{d} x_{S}}{\mathrm{~d} t}=-k_{1} x_{S} \\
\frac{\mathrm{d} x_{V}}{\mathrm{~d} t}=k_{2} x_{B}-k_{3} x_{V}
\end{aligned}
$$

\subsection{Model 3}

The reaction mechanism of model 3 was assumed as shown in fig. 4.

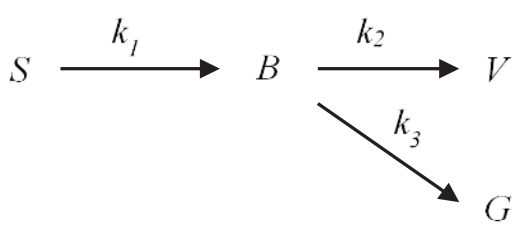

Fig. 4.. Reaction scheme of model 3.

The kinetic equations of the model were as follows.

$\frac{\mathrm{d} x_{B}}{\mathrm{~d} t}=k_{1} x_{S}-k_{2} x_{B}-k_{3} x_{B}$

$\frac{\mathrm{d} x_{G}}{\mathrm{~d} t}=k_{3} x_{B}$

$\frac{\mathrm{d} x_{S}}{\mathrm{~d} t}=-k_{1} x_{S}$

$$
\frac{\mathrm{d} x_{V}}{\mathrm{~d} t}=k_{2} x_{B}
$$

\subsection{Model 4}

The reaction mechanism of model 4 was assumed as shown in fig. 5 .

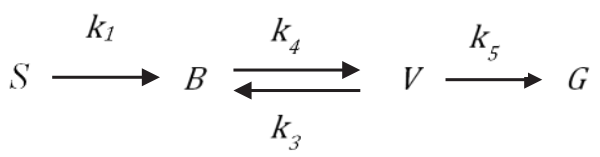

Fig. 5. Reaction scheme of model 4.

The kinetic equations of the model were as follows.

$\frac{d x_{B}}{d t}=k_{1} x_{S}+k_{3} x_{V}-k_{4} x_{B}$

$\frac{d x_{G}}{d t}=k_{5} x_{V}$

$\frac{d x_{S}}{d t}=-k_{1} x_{S}$

$\frac{d x_{V}}{d t}=-k_{3} x_{V}+k_{4} x_{B}-k_{5} x_{V}$

$k_{j}$ is the reaction rate constant, where $j$ is the reaction number. $k_{j}$ is depend on the temperature $(T)$ of the reaction system, and it is described by Arrhenius equation:

$k_{j}=A_{j} \exp \left(-\frac{E_{j}}{R T}\right)$

where $A_{j}$ is the pre-exponential factor, $E_{j}$ is the activation energy, $R$ is the gas constant.

The sistem temperature was not constant or time dependent as the process was non-isothermal. The correlation of temperature $(T)$ and time $(t)$ was discribed by equation (22).

$T(t)= \begin{cases}a+b t, & t \leq t_{1} \\ T_{0}+c t^{d}, & t_{1}<t \leq t_{2} \\ T_{1}, & t>t_{2}\end{cases}$

where $a, b, c, d, T_{0}, T_{1}, t_{1}$, and $t_{2}$ was determined by the experimental data.

The unknown kinetic parameters $\left(A_{j}, E_{j}\right)$ were estimated by the nonlinear least square method, with the following objective function (i.e., the sum of the squares of the differences between the calculation results and the experimental data): 


$$
S S E=\sum_{i=1}^{N}\left(\begin{array}{l}
\left(x_{B \text { cal }, i}-x_{B \text { dat }, i}\right)^{2}+\left(x_{G \text { cal }, i}-x_{G \text { dat }, i}\right)^{2} \\
+\left(x_{S c a l, i}-x_{S d a t, i}\right)^{2}+\left(x_{V \text { cal }, i}-x_{V \text { data }, i}\right)^{2}
\end{array}\right)
$$

SSE is sum of squared errors. In equation (23), the subscripts "cal" and "dat" represent the calculation and the experimental results, respectively. $\mathrm{N}$ is the total number of experimental data.

The kinetic parameters $\left(A_{j}, E_{j}\right)$ were obtained by minimizing of equation (23). The kinetic equations were simultaneous first order differential equation, which were solved by Runge-Kutta method with initial condition $x_{S}=1$ and $x_{B}=x_{G}=x_{V}=0$ to estimate the yield of the products $\left(x_{B}, x_{G}, x_{S}, x_{V}\right)$ each time interval.

\section{Results and discussion}

This section reports the evaluation of the kinetic models and the effects of ethanol concentration, based on the actual products yield from experimental data with variations in ethanol concentrations.

\subsection{Evaluation of kinetic models}

The four kinetic models were applied to the three experimental data with variation in ethanol concentration. The best model was determined based on the smallest sum of squared errors (SSE) and mean absolute errors (MAE). The SSE and the MAE values of each model are shown in table 1 . Table 1 shows that model 4 has the smallest SSE and MAE values, so model 4 is considered the best model that can approach experimental data.

Table 1. The sum of squared errors (SSE) and the mean of absolute errors (MAE) of the models.

\begin{tabular}{|c|c|c|}
\hline Model & SSE & MAE \\
\hline 1 & 0.0093 & 1.4886 \\
\hline 2 & 0.0045 & 0.8819 \\
\hline 3 & 0.0049 & 0.9140 \\
\hline 4 & 0.0043 & 0.8803 \\
\hline
\end{tabular}

Model 4 was tried to be applied to the experimental data. One of the experimental data, the products yield with ethanol concentration of $20 \%$ and the calculation results with model 4 , is shown in fig. 6 . It is seen that the experimental data was approached quite well by model 4.

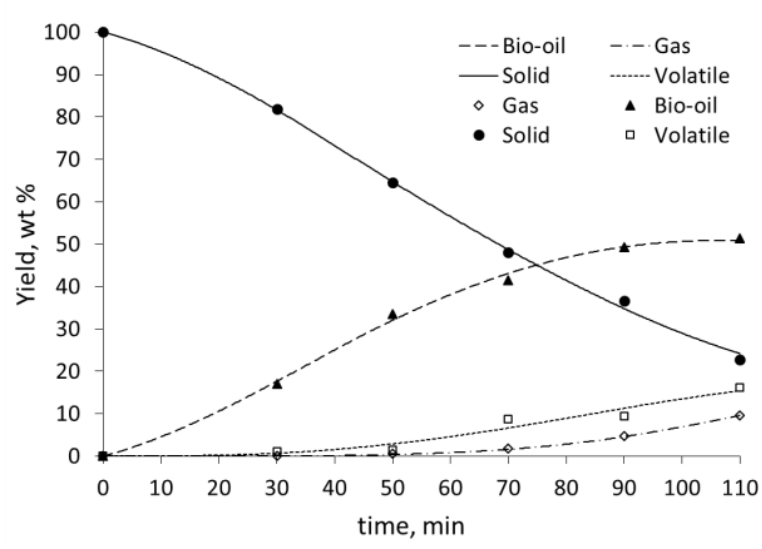

Fig. 6. Experimental data (discrete point) and calculated (continuous curves) product yields with model 4 using ethanol concentration of $20 \%$.

\subsection{Effect of ethanol concentration}

The effect of ethanol concentration was studied with model 4 approach, which was selected as the most appropriate model. Fig. 7 and 8 shows the difference in the yield of bio-oil products due to different ethanol concentrations. The three curves show that when the reaction time reached 100 minutes the bio-oil yield reached the maximum value. In that case, the production of bio-oil reached equilibrium. Using ethanol solution from $0 \%$ to $40 \%$ was able to increase the maximum biooil yield from $42.05 \%$ to $54.93 \%$.

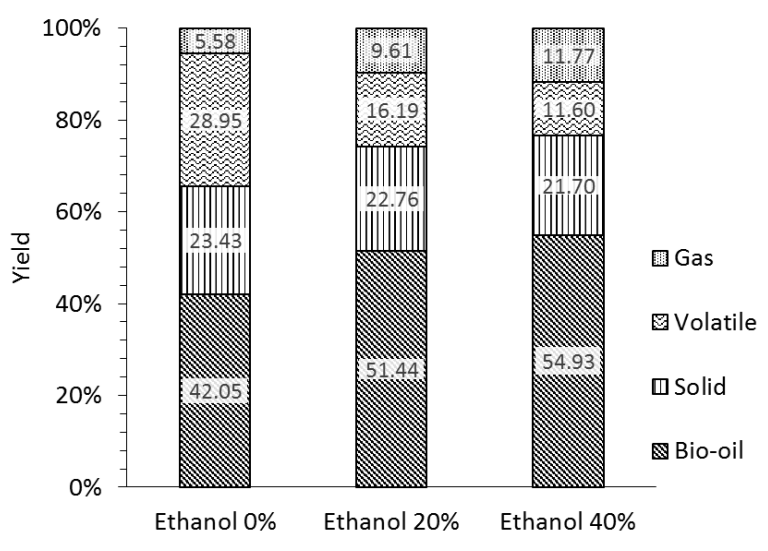

Fig. 7. Yield of the products at the end of liquefaction process with different concentration of water-ethanol solution.

The biomass conversion can be calculated by substracting $100 \%$ with the percent yield of solid product. In fig. 7 and 9, we can see that the increase in ethanol concentrations had no significant effect on the increase in biomass conversion, which only increased from $76.57 \%$ to $78.3 \%$. The increase in bio-oil yield was not obtained from the increase in biomass decomposition rate, but it was obtained from the decrease in volatile production from $28.95 \%$ to $21.7 \%$ (fig. 7 and 10 ). Thus, the increase in ethanol concentration could decrease the rate of volatile formation as well as encouraging the rate of bio-oil formation. 


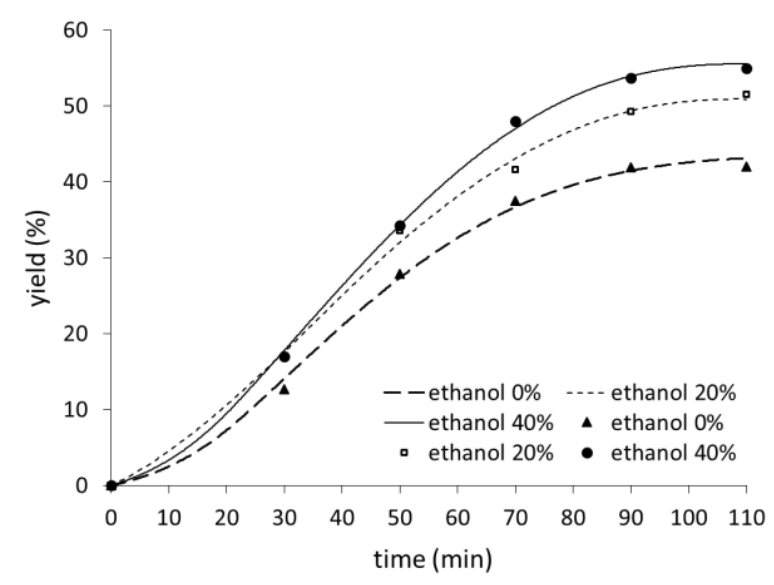

Fig. 8. Profile of bio-oil yield against time with variation of ethanol concentration.

The research results of Zhang and Zhang [13], Chen et al. [14], Yuan et al. [15], and Cheng, et al. [16] also showed the synergistic effect of co-solvent ethanol on the increase in bio-oil production of thermochemical liquefaction processes, although each used different biomass feedstocks.

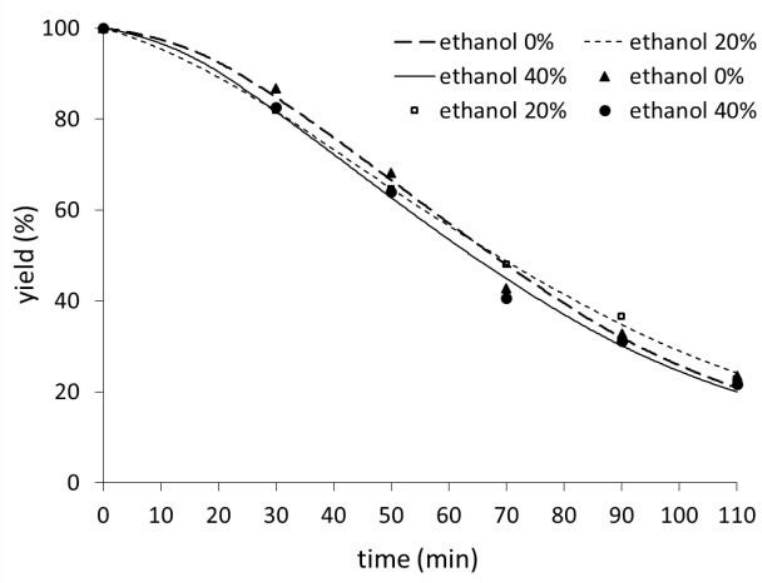

Fig. 9. Profile of solid yield against time with variation of ethanol concentration.

Chen et al. [14] stated that the conversion and yield bio-oil of Dunaliella tertiolecta reached a maximum by using $40 \%$ ethanol solution at $320^{\circ} \mathrm{C}$, but decreased if the concentration of ethanol was more than $40 \%$. Biomass conversion reached $98.24 \%$ and maximum bio-oil yield reached $64.68 \%$.

The results of Yuan et al. [15], which examined the effect of ethanol concentration on rice stalk liquefaction, showed that the bio-oil yield reached the maximum value with $50 \%$ ethanol solution at $300^{\circ} \mathrm{C}$. The result was similar to the research of Cheng et al. [16] on the liquefaction of pine wood in ethanol solution, which had result that the maximum bio-oil yield $(65 \%)$ could be achieved with $50 \%$ ethanol solution at $300^{\circ} \mathrm{C}$.

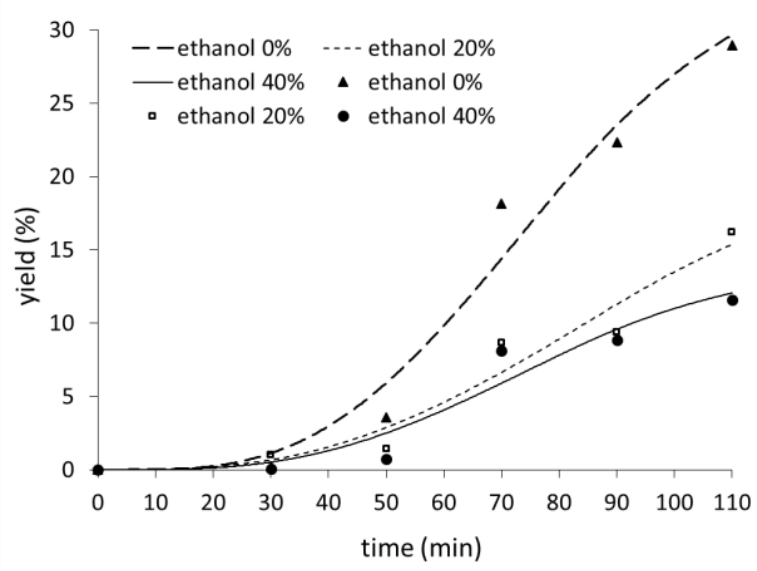

Fig. 10. Profile of volatile yield against time with variation of ethanol concentration.

According to Chen et al. [14], the presence of ethanol caused the reaction of ethanol with amides and carboxylic acids to form ethyl ester, which was quite abundant in bio-oil. In addition, ethanol also becomes a hydrogen donor in liquefaction process.

The gas yield increased from $5.58 \%$ to $11.77 \%$ with the addition of ethanol concentration up to $40 \%$ (fig. 7 and 11). This result differed from that of Cheng et al. [16], which had result that the yield of gas did not changed much with the addition of ethanol concentration, except at the concentration of ethanol close to $100 \%$, where gas yield decreased slightly.

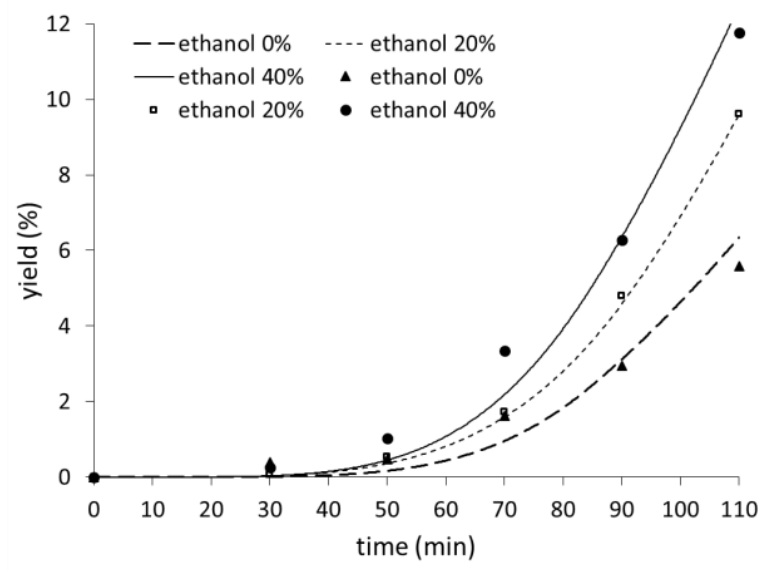

Fig. 11. Profile of gas yield against time with variation of ethanol concentration.

Although the addition of ethanol concentration up to $40 \%$ could increase the bio-oil yield up to $54.93 \%$, it is recommended that the ethanol concentration applied is $20 \%$ for economic reasons. The increase in bio-oil yield with the addition of ethanol concentration from $20 \%$ to $40 \%$ was not significant, compared to the increase in price of ethanol.

The effect of addition of ethanol concentration was also seen in the activation energy value of biomass decomposition reaction $\left(\mathrm{E}_{1}\right)$ to bio-oil which decreased from $19,927.2 \mathrm{~J} / \mathrm{mol}$ to $16,158.1 \mathrm{~J} / \mathrm{mol}$ (table 2 ). The decrease in the activation energy resulted in the increase in the rate of bio-oil formation. 
Table 2. The energy activations, E $(\mathrm{J} / \mathrm{mol})$, from calculation with model 4.

\begin{tabular}{|c|c|c|c|c|}
\hline $\begin{array}{c}\text { Ethanol } \\
\text { Concen- } \\
\text { tration }\end{array}$ & $\mathbf{E}_{\mathbf{1}}$ & $\mathbf{E}_{\mathbf{3}}$ & $\mathbf{E}_{\mathbf{4}}$ & $\mathbf{E}_{\mathbf{5}}$ \\
\hline $0 \%$ & 19927.2 & 27459.8 & 26641.5 & 34205.7 \\
\hline $20 \%$ & 17591.8 & 34704.4 & 24385.4 & 25692.5 \\
\hline $40 \%$ & 16158.1 & 28473.9 & 24380.7 & 23931.5 \\
\hline
\end{tabular}

\section{Conclusions}

The kinetics study on non-isothermal thermochemical liquefaction of corncobs in ethanol-water solution had been performed for the effect of ethanol concentration. From the reaction without ethanol (or only water) to the reaction with ethanol concentration up to $40 \%$, the activation energy decreased from $19,927.2 \mathrm{~J} / \mathrm{mol}$ to $16,158.1 \mathrm{~J} / \mathrm{mol}$, so the reaction rate constant increased as well as the reaction rate to form bio-oil. Though, it was the highest yield of bio-oil achieved, but it was suggested to use ethanol concentration up to $20 \%$ for the economic reasons. Model 4 was found to be the best one for approaching the experimental data of thermochemical liquefaction of corncobs in the ethanolwater solution. In model 4 the reaction mechanism was assumed that biomass (corncobs) first decomposes into bio-oil, followed by decomposition of bio-oil into volatile products reversibly and finally volatile products decompose into gaseous products.

The author was very thankful to Universitas Sebelas Maret for the financial support from doctoral and post doctoral research grant to carry out this research work.

\section{References}

1. P.S. Nigam, A. Singh, Prog. Energ. Combust. 37, 52 (2011)

2. A. Dimitriadis, S. Bezergianni, Renew. Sust. Energ. Rev. 68, 113 (2017)

3. R. Singh, B. Balagurumurthy, A. Prakash, T. Bhaskar, Bioresour. Technol. 178, 157 (2015)

4. Z. Liu, F.S. Zhang, Energ. Convers. Manage. 49, 3498 (2008)

5. Y. Wang, H. Wang, H. Lin, Y. Zheng, J. Zhao, A. Pelletier, K. Li, Biomass Bioenerg. 59, 158 (2013)

6. Y. Yan, M. Hu, Z. Wang, Ind. Crops Prod. 32, 349 (2010)

7. Y. Shi, J. Li, J. Wang, T. Zhao, H. Yang, J. Jiang, X. Jiang, Bioresour. Technol. 214, 419 (2016)

8. B. Zhang, H.J. Huang, S. Ramaswamy, Energ. Source. Part A 34, 1676 (2012)

9. H. Zhang, H.Yang, H. Guo, C. Huang, L. Xiong, X. Chen, Appl. Energ. 113, 1596 (2014)

10. J. Zhang, B. Jiang, D. Wang, Algal Res. 18, 45 (2016)

11. J. Gan, W. Yuan, Appl. Energ. 103, 350 (2013)
12. P.J. Valdez, P.E. Savage, Algal Res. 2, 416 (2013)

13. J. Zhang, Y. Zhang, Energy Fuels 28, 5178 (2014)

14. Y. Chen, Y. Wu, P. Zhang, D. Hua, M. Yang, C. Li, Z.Chen, J. Liu, Bioresour. Technol. 124, 190 (2012)

15. X.Z. Yuan, H. Li, G.M. Zeng, J.Y. Tong, W. Xie, Energy 32, 2081 (2007)

16. S. Cheng, I. D'cruz, M. Wang, M. Leitch, C. Xu, Energy Fuels 24, 4659 (2010) 